\title{
Attenuated form of type II mucopolysaccharidoses (Hunter syndrome): pitfalls and potential clues in diagnosis
}

\author{
Partha Pratim Chakraborty, Shinjan Patra, Sugata Narayan Biswas, Himanshu Barman
}

Department of Medicine, Midnapore Medical College and Hospital, Midnapore, India

\section{Correspondence to} Dr Partha Pratim Chakraborty, docparthapc@yahoo.co.in

Accepted 6 February 2018

\section{DESCRIPTION}

A 7-year-old boy, born of a non-consanguineous union, presented with pain over both hips and progressive difficulty in walking for preceding 2 years. He had normal developmental milestones with satisfactory scholastic performances and his family and perinatal histories were unremarkable. Clinical examination revealed short stature (height SD score (SDS): -2.3 ; midparental height (MPH) SDS: -1.7) with upper segment (US):lower segment (LS) ratio of 0.97 , umbilical hernia, apical pansystolic murmur of mitral regurgitation and waddling gait without corneal opacity or organomegaly (figure 1). Complete blood count, baseline biochemistry and thyroid function tests were normal except presence of azurophilic granules within white blood cells seen in peripheral blood smear (figure 2). Transthoracic echocardiography confirmed moderate mitral regurgitation secondary to prolapsed posterior mitral leaflet leading to coaptation failure. Though the difference between his height centile and MPH centile was not striking, his body proportion was suggestive of short trunk dwarfism (US:LS is normally 1.4 at 1 year and 1 at 10 years of age). A whole-body skeletal survey was advised that documented oar-shaped ribs, anterior beaking of vertebral bodies and bulletshaped metacarpals along with dysplastic acetabulae (figures 3-5). Urinary mucopolysaccharidoses (MPS) screen by toluidine blue spot test was negative. Enzyme assay revealed reduced activity of iduronate-6-sulfatase.

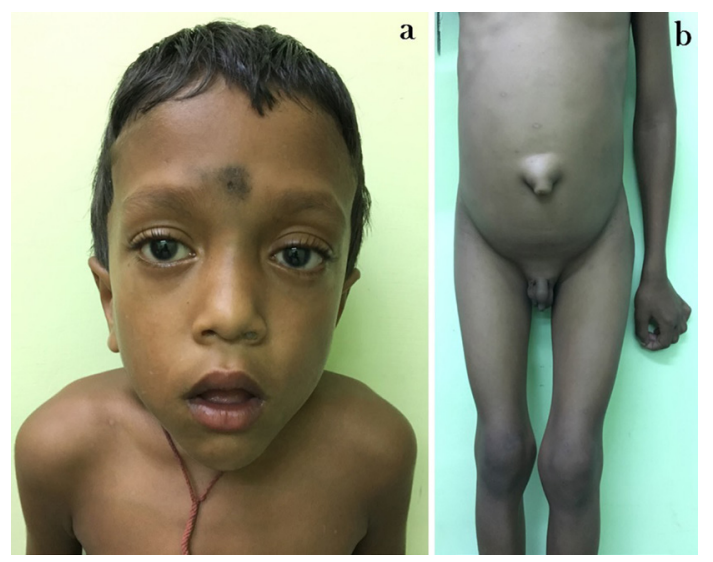

Patra S, Biswas SN, et al. BM Case Rep Published Online First: [please include Day Month Year]. doi:10.1136/ bcr-2018-224392

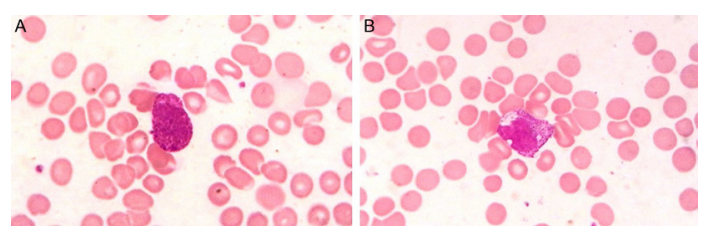

Figure 2 Azurophillic granules within neutrophil (A) and monocyte (B).

MPS are a group of storage disorder in which deficiency of one of the several enzymes required for stepwise breakdown of glycosaminoglycans (GAG) within the lysosomes results in accumulation of partially degraded GAGs in different organs and their dysfunction. MPS II or Hunter syndrome, an X linked disorder, is caused by deficiency of iduronate-2-sulfatase and is the most common form of MPS. ${ }^{1}$ The severe form is characterised by short stature, coarse facial features, hepatosplenomegaly and a number of skeletal deformities termed as 'dysostosis multiplex' in addition to neurological and cardiovascular abnormalities. The attenuated form on the other hand has subtle clinical features, hence difficult to pick up in clinical practice. Unlike other forms of MPS, patients with Hunter syndrome have later onset of disease, slower clinical course and no corneal clouding adding further difficulties in diagnosis. The boy did not have suggestive facial appearance or other commonly encountered systemic findings of MPS. Peripheral blood smear and the skeletal survey provided us with the important diagnostic clues.

Attenuated forms of MPS can be easily overlooked because of paucity of clinical signs. Moreover, they are often misdiagnosed as LeggCalve-Perthes disease or skeletal dysplasia in presence of prominent skeletal abnormalities and lack of involvement of other systems. Urinary spot test, though cheap and commonly used in resource-restricted setting, has poor sensitivity. So, appropriate patients should ideally be screened either with quantitative measurement of total urinary GAG or qualitative analysis by electrophoresis or chromatography to identify the specific GAG. Such analysis, however, is costly and has its own limitations. ${ }^{2}$ In addition, some types of MPS (III and IV) may have false negative urinary GAG. Azurophilic cytoplasmic inclusions in neutrophils, lymphocytes and monocytes (Alder-Reilly granules) have been described in MPS and rarely in myelodysplasia and myeloperoxidase mutations. ${ }^{3}$ 

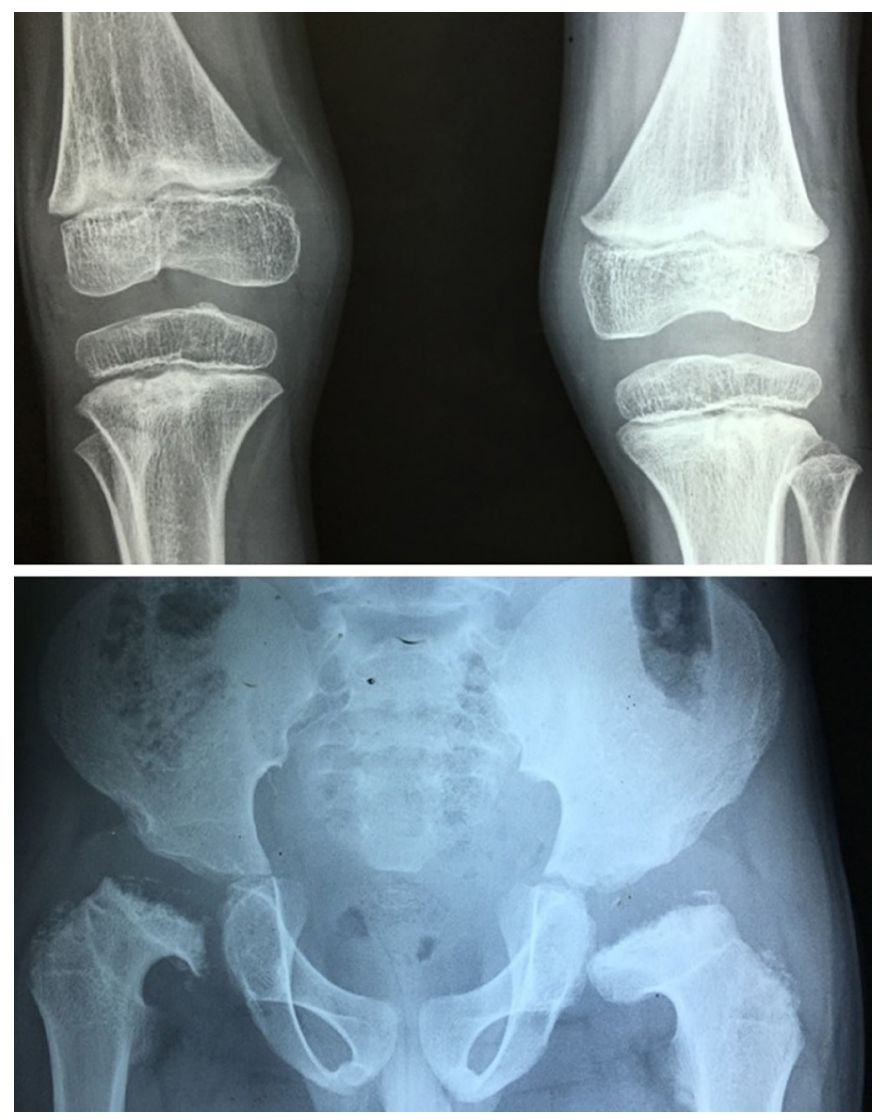

Figure 3 Irregular and hyperostotic metaphysis due to inadequate remodelling (upper panel) and dysplastic acetabuli (lower panel).

Careful evaluations of peripheral blood smear supplemented with skeletal survey are thus cost-effective tools to provide important clue to the underlying MPS.

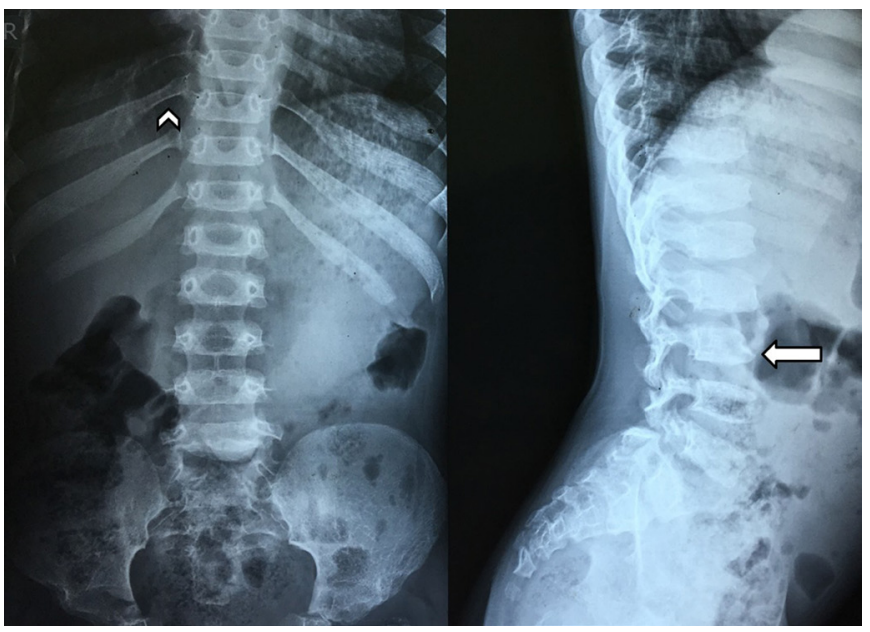

Figure 4 Oar-shaped ribs (narrowing near the vertebral column and a broadened anterior end) (arrowhead in left panel) and beaked appearance of $L 3$ vertebral body in the anteroinferior surface (arrow in right panel).

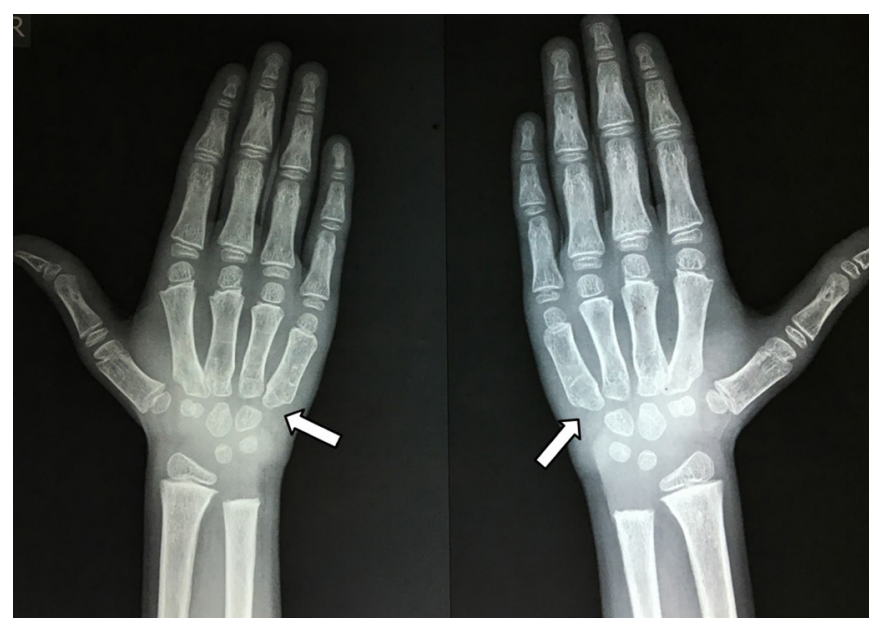

Figure 5 Bullet-shaped metacarpals (metacarpals that are narrow proximally and wide distally) (arrow).

\section{Learning points}

- Unlike most patients with mucopolysaccharidoses (MPS) individuals with Hunter syndrome (MPS-II) do not have corneal clouding. In addition, relatively late onset of the disease and absent/minimal clinical signs in the attenuated forms pose great difficulties for the clinicians to suspect such condition.

- Quantitative measurement or qualitative analysis of urinary glycosaminoglycan (GAG) by electrophoresis or chromatography, the recommended screening tests for MPS are costly and may not be available in the developing countries. Moreover, they can be potentially misleading in certain types of MPS or in the attenuated forms where the total urinary GAG excretion is relatively low.

- Alder-Reilly granules are azurophilic cytoplasmic inclusions found in peripheral blood leucocytes and often misdiagnosed as toxic granules. Though they are not specific to MPS and have also been described in myeloperoxidase mutations and myelodysplasia, they are an important clue to underlying MPS.

- Whole-body skeletal survey documenting 'dysostosis multiplex' is another useful and cost-effective diagnostic tool in addition to peripheral blood smear to diagnose MPS in the developing world.

Contributors PPC, SP, SNB and HB were involved in patient evaluation and management. PPC and SP also did the literature search and wrote the manuscript.

Competing interests None declared.

Patient consent Guardian consent obtained.

Provenance and peer review Not commissioned; externally peer reviewed.

(c) BMJ Publishing Group Ltd (unless otherwise stated in the text of the article) 2018. All rights reserved. No commercial use is permitted unless otherwise expressly granted.

\section{REFERENCES}

1 Khan SA, Peracha H, Ballhausen D, et al. Epidemiology of mucopolysaccharidoses. Mol Genet Metab 2017;121:227-40.

2 López-Marín L, Gutiérrez-Solana LG, Azuara LA, et al. Detection by urinary GAG testing of mucopolysaccharidosis type II in an at-risk Spanish population. JIMD Rep 2013;10:61-8.

3 Lukefahr AL, Proytcheva M. Alder-reilly anomaly in the cerebrospinal fluid of a child with hurler syndrome. J Pediatr Hematol Oncol 2018;40:74-5. 
Copyright 2018 BMJ Publishing Group. All rights reserved. For permission to reuse any of this content visit http://group.bmj.com/group/rights-licensing/permissions.

BMJ Case Report Fellows may re-use this article for personal use and teaching without any further permission.

Become a Fellow of BMJ Case Reports today and you can:

- Submit as many cases as you like

- Enjoy fast sympathetic peer review and rapid publication of accepted articles

Access all the published articles

Re-use any of the published material for personal use and teaching without further permission

For information on Institutional Fellowships contact consortiasales@bmjgroup.com

Visit casereports.bmj.com for more articles like this and to become a Fellow 